\title{
Notch1 signaling pathway promotes invasion, self-renewal and growth of glioma initiating cells via modulating chemokine system CXCL12/CXCR4
}

Li Yi ${ }^{1,2+}$, Xingchen Zhou ${ }^{3+}$, Tao Li ${ }^{1,2 \dagger}$, Peidong Liu ${ }^{1,2}$, Long Hai ${ }^{4}$, Luqing Tong ${ }^{1,2}$, Haiwen Ma ${ }^{1,2}$, Zhennan Tao ${ }^{1,2}$, Yang $\mathrm{Xie}^{1,2}$, Chen Zhang ${ }^{5}$, Shengping $\mathrm{Yu}^{1,2}$ and Xuejun Yang ${ }^{1,2^{*}}$

\begin{abstract}
Background: Glioma initiating cells (GICs), also known as glioma stem cells (GSCs), play an important role in the progression and recurrence of glioblastoma multiforme (GBM) due to their potential for self-renewal, multiple differentiation and tumor initiation. In the recent years, Notch1 has been found to be overexpressed in GICs. However, the regulatory mechanism of Notch1 in the self-renewal and invasion ability of GICs remains unclear. This study aims to explore the effect of Notch pathway on self-renewal and invasion of GICs and the underlying mechanisms.

Methods: Bioinformatic analysis and immunohistochemistry $(\mathrm{IHC})$ were performed to evaluate the expression of Notch1 and Hes1 in GBM samples. Immunofluorescent (IF) staining was performed to observe the distribution of Notch1 and CXCR4 in GBM and GICS. Both pharmacological intervention and RNA interference were employed to investigate the role of Notch1 in GICs self-renewal, invasion and tumor growth in vitro or in vivo. The crosstalk effect of Notch1 and CXCL12/CXCR4 system on GIC self-renewal and invasion was explored by sphere formation assay, limiting dilution assay and Transwell assay. Western blots were used to verify the activation of Notch1/ CXCR4/AKT pathway in self-renewal, invasion and tumor growth of GICs. Luciferase reporter assay was used to testify the potential binding site of Notch1 signaling and CXCR4. The orthotopic GICs implantations were established to analyze the role and the mechanism of Notch1 in glioma progression in vivo.
\end{abstract}

Results: Notch1 signaling activity was elevated in GBM tissues. Notch1 and CXCR4 were both upregulated in GICs, compared to Notch1 positive glioma cells comprised a large proportion in the CD133+ glioma cell spheres, CXCR4 positive glioma cells which usually expressed Notch1 both and dispersed in the periphery of the sphere, only represent a small subset of CD133+ glioma cell spheres. Furthermore, downregulation of the Notch1 pathway by shRNA and MK0752 significantly inhibited the PI3K/AKT/mTOR signaling pathway via the decreased expression of CXCR4 in GICs, and weakened the self-renewal, invasion and tumor growth ability of GICs.

Conclusions: These findings suggest that the cross-talk between Notch1 signaling and CXCL12/CXCR4 system could contribute to the self-renewal and invasion of GICs, and this discovery could help drive the design of more effective therapies in Notch1-targeted treatment of GBMs.

Keywords: Glioma initiating cells, Notch1, CXCR4, Invasion, Migration

\footnotetext{
* Correspondence: ydenny@126.com

${ }^{+} \mathrm{Li}$ Yi, Xingchen Zhou and Tao Li contributed equally to this work.

'Department of Neurosurgery, Tianjin Medical University General Hospital,

Tianjin 300052, China

${ }^{2}$ Laboratory of Neuro-Oncology, Tianjin Neurological Institute, Tianjin 300052,

China

Full list of author information is available at the end of the article
}

(c) The Author(s). 2019 Open Access This article is distributed under the terms of the Creative Commons Attribution 4.0 International License (http://creativecommons.org/licenses/by/4.0/), which permits unrestricted use, distribution, and reproduction in any medium, provided you give appropriate credit to the original author(s) and the source, provide a link to the Creative Commons license, and indicate if changes were made. The Creative Commons Public Domain Dedication waiver (http://creativecommons.org/publicdomain/zero/1.0/) applies to the data made available in this article, unless otherwise stated. 


\section{Background}

Glioblastoma multiforme (GBM), the most common primary malignancy of the brain, is an aggressive tumor with a poor prognosis. Due to its complex heterogeneity, plasticity and therapy resistance, GBM remains one of the most difficult tumors to treat, with a 5-year survival rate of only approximately $5.5 \%$ [1], despite the progress made in surgery combined with radiotherapy and chemotherapy in the last decade [2]. Glioma initiating cells (GICs) is a group of tumor cells with self-renewal, unlimited proliferation and multi-differentiation abilities, GICs are often located in the hypoxic niche, perivascular niche and invasive niche [3-5]. Many studies have shown that GICs are probably involved in the initiation, development, invasion and migration of tumors, as well as in resistance to chemotherapeutic agents, leading to tumor recurrence [6]. Therefore, a better definition of how GICs interact with their microenvironment would facilitate understanding the basic biology of the tumor and the design of more effective therapies.

In recent years, Notch1 has been found to be overexpressed in GICs, and the Notch pathway plays a vital role in the stem maintenance of glioma cells [7, 8]. The family of Notch receptors consist of heterodimeric transmembrane proteins intimately involved in the determination of cell fate. Up to now, four Notch receptors have been identified in humans (Notch1-4), with five corresponding ligands including Delta-like-1, Delta-like-3, Delta-like-4, Jagged-1, and Jagged-2. Activation of the Notch pathway requires that the receptor bind to the ligand and undergo protease hydrolysis to produce the Notch intracellular domain (NICD), which is released into the nucleus and go through a series of reactions to activate downstream HES and HEY, thus, the corresponding biological effects are produced. Hes1 is commonly used as a biomarker of Notch1 pathway activation [9, 10]. Depending on the cell types, Notch signaling can positively or negatively influence proliferation, differentiation, and apoptosis [9]. It was also demonstrated that Notch promoted radio-resistance in glioma stem cells [11]. Unfortunately, targeting developmental pathways such as Notch will most likely not give us the elusive "magic bullet", as most of the trials on Notch inhibitors remain in clinical phases I and II [12], and will require to develop rational combinations. Such combinations will be made possible only through a better understanding of the crosstalk between Notch and other molecules that may play roles in GICs in specific malignancies [13].

CXCR4, a cell surface chemokine receptor, is implicated in the growth, invasion, angiogenesis and metastasis in a wide range of malignant tumors, including leukaemia, breast cancer and very recently in glioma [14-17]. Interestingly, CXCR4 has been shown to be selectively present on cancer initiating cells (CICs) derived from several solid tumors and they play a critical role in regulating carcinogenesis $[18,19]$. The few studies that have looked into the role of CXCR4 in GICs, proposed that CXCR4 positive cells have the capability of developing not only tumorspheres in serum-free medium (SFM) supplemented with growth factors, but also the other cardinal features required for a GIC population [16, 20, 21]. Targeting CXCL12/CXCR4 autocrine/ paracrine loop could inhibit the survival and proliferation of glioma stem cells and drive the migration of GSCs to neurogenic zone [22, 23]. Additionally, Notch signaling has been implied in mediating chemotaxis system CXCL12/CXCR4 in the metastasis renal cell carcinoma and multiple myeloma $[24,25]$. However, the regulatory mechanism of Notch1 and its crosstalk with CXCL12/CXCR4 in GICs remains unclear. In this study, we highlighted that blocking Notch1 signaling by MK0752 (a $\gamma$-secretase inhibitor) or shRNA weakened the invasion and growth of GICs, these effects were reversed by the CXCR4 stimulating factor CXCL12. In addition, Notch1 signaling could enhance transcription of CXCR4 through directly targeting its promoter by RBPJ. Collectively, our findings confirmed that Notch1 promotes GICs invasion self-renewal and tumor growth through the AKT/mTOR pathway mediated by CXCL12/CXCR4 axis and thus provide evidence of a promising target for GBM management.

\section{Methods}

\section{Cell lines and cell culture}

U87 and U251 glioma cells were purchased from the Institute of Biochemistry and Cell Biology (Shanghai, China). Cells were cultured in DMEM containing 10\% FBS (Gibco, USA). After MACS, CD133+ cells were cultured in stem cell medium (DMEM/F12 medium supplemented with $20 \mathrm{ng} / \mathrm{ml} \mathrm{EGF,} 20 \mathrm{ng} / \mathrm{ml} \mathrm{bFGF}$, and B27 (1, 50, Invitrogen, USA)). The tumorsphere can be observed on the second day.

\section{Magnetic activated cell sorting}

CD133+ glioma cells were collected by CD133 Micro Bead Kit (Miltenyi, Germany) The tumorspheres were cultured for 7 days, centrifuged, removed, and digested with $0.25 \%$ Trypsin-EDTA. After $0.5 \mathrm{~min}$, the complete medium was added to terminate the digestion. After centrifugation, the supernatant was removed, to further reduce the interference of serum, serum-free DMEM/ F12 medium was added to make a single cell suspension. The cell concentration was adjusted to $1 \times 10^{5}$ cells $/ \mu$, $300 \mu \mathrm{l}$ of the cell suspension, $100 \mu \mathrm{l}$ of FcR and $100 \mu \mathrm{l}$ of CD133 beads were added to PBS buffer supplemented with $5 \%$ fetal bovine serum and $2 \mathrm{mM}$ EDTA, thoroughly followed by incubation at $4{ }^{\circ} \mathrm{Cin}$ the refrigerator 
for $30 \mathrm{~min}$. After installation of the magnetic separation column and iron, the prepared cells were added to the cell separation column with $500 \mu \mathrm{l}$ buffer filtered 4 times to obtain unlabelled cells. Finally, to remove the iron from the magnetic separation column, $1 \mathrm{ml}$ of buffer was used to flush the column, then, the obtained CD133+ labeled cells were cultured in stem cell medium.

\section{Lentiviral transfection}

Lentiviral shRNA constructs were obtained from GeneChem Co., Ltd., China. shRNA sequences were as follows: GCATGGTGCCGAACCAATACA (NOTCH1shRNA1), GGAGCATGTGTAACATCAACA (NOTCH1shRNA2). Cells were transfected with the lentiviral particles, according to the manufacturer's recommendations. After infection, stable cell clones expressing the shRNA constructs were isolated by selection with $5 \mu \mathrm{g} / \mathrm{ml}$ puromycin solution. Cells were collected for further experiments at $48 \mathrm{~h}$ after the transfection.

\section{Patient data analysis}

Patient data and gene expression datasets were obtained from Oncomine Datasets Platform (https://www.onco mine.org/resource/login.html). Funrich software (http:// www.funrich.org/) was used as the tool for making heatmap. Twenty-seven panels of GICs and 36 panels of nonglioma initiating cells (NGICs) were downloaded from Microarray data of GEO (Accession No. GSE23806). Boxplot, Kaplan-Meier analysis and the resulting survival curves were performed using GraphPad Prism (version 6.0). All cut-off values for separating high and low expression groups were determined by median expression value.

\section{Immunofluorescence analysis}

An original method was applied to label proteins in the glioma tumorspheres. Tumorspheres were placed into a cell insert (Millipore, US) and fixed with $0.4 \%$ paraformaldehyde solution (Solarbio, China). Then, the tumorspheres were washed three times with PBS, and incubated with primary antibodies overnight at $4{ }^{\circ} \mathrm{C}$. Alexa-Fluor 488 conjugated anti-rabbit secondary antibody (1:1000, Life Technologies, USA) and Alexa-Fluor 594 conjugate anti-mouse secondary antibody $(1,1000$, Life Technologies, USA) were used for fluorescent doublestaining. DAPI solution (Solarbio, China) was employed to label cell nuclei.

\section{Immunohistochemistry staining}

Paraffin embedded tumor tissues were sectioned at $6 \mu \mathrm{m}$, deparaffinized, and rehydrated. For antigen retrieval, sections were treated for $20 \mathrm{~min}$ at $95^{\circ} \mathrm{C}$ with $10 \mathrm{mmol} / \mathrm{L}$ citrate buffer ( $\mathrm{pH} 6.0)$ in a laboratory microwave oven and subsequently washed with PBS. For immunohistochemistry, after quenching the endogenous peroxidase activity and blocking with normal goat serum, sections were incubated sequentially with the primary antibodies at $4{ }^{\circ} \mathrm{C}$ overnight, the next day, after rewarming for $1 \mathrm{~h}$, sections were incubated with secondary antibodies (ZSGB-Bio, China) for $1 \mathrm{~h}$ at $37^{\circ} \mathrm{C}$. Immunostaining was performed using two-steps detection kit (ZSGB-Bio, China), which resulted in a brown precipitate at the antigen site. Subsequently, sections were counterstained with Mayer Haematoxylin solution (ZSGBBio, China) and mounted in mounting medium. The primary antibody was omitted for the negative controls. After dehydration, sections were examined using a light microscope. Protein expression levels were quantified on the basis of a multiplicative index of the staining extent $(0-3)$ and the average staining intensity $(0-3)$. The staining score is the product of staining extent and the staining intensity.

\section{In vitro migration and invasion assays}

Cells $\left(5 \times 10^{5}\right)$ were plated on the top side of polycarbonate Transwell filters (for migration assay) or on the top side of polycarbonate Transwell filters coated with Matrigel (for invasion assay) in the top chamber of a 24well cell invasion assay (Coning, USA). Dissociated GICs were seeded into chambers, the cells were suspended in medium without serum, and medium supplemented with stem cell culture medium $(20 \mathrm{ng} / \mathrm{ml}$ EGF, $20 \mathrm{ng} / \mathrm{ml}$ bFGF, and 1,50 B27) was used as a chemoattractant in the bottom chamber. The cells were incubated at $37^{\circ} \mathrm{C}$ for $24 \mathrm{~h}$ (for migration assay) or $48 \mathrm{~h}$ (for invasion assay). The non-migratory or non-invasive cells in the top chambers were removed with cotton swabs. The cells that migrated and invaded the lower membrane surface were fixed in $4 \%$ paraformaldehyde for $10 \mathrm{~min}$, air-dried, then stained crystal violet staining solution (Solarbio, China) and counted under a microscope at a $10 \times$ magnification.

\section{Western blotting analysis}

Cells were lysed in RIPA buffer (Solarbio, China) containing PMSF (dilution, 1:100; Solarbio, China), and proteins were extracted from cells cultured in the absence of FBS. Before denaturation, total protein concentration was determined using BCA protein assay kit (Solarbio, China), according to the manufacturer's instructions. The extracted proteins were separated by performing sodium dodecyl sulfate-polyacrylamide gel electrophoresis (SDSPAGE), blotted onto PVDF membranes (Millipore, USA), and incubated overnight at $4{ }^{\circ} \mathrm{C}$ with the indicated primary antibodies: Anti-Notch1 (Abcam, 1:1000), AntiNICD (Abcam, 1:1000), Anti-Hes1 (Abcam, 1:1000), AntiCXCR4 (Abcam, 1:1000), Anti-Akt (cell signaling, 1:1000), Anti-pAkt (cell signaling, 1:1000), Anti-mTOR (cell signaling, 1:1000), Anti-pmTOR (cell signaling, 1:1000). Next, the membranes were washed and incubated with 
goat anti-rabbit/mouse IgG secondary antibody (dilution, 1:2000) for $1 \mathrm{~h}$ at room temperature. Protein expression was analyzed using GBOX (Syngene Company, UK) and a chemiluminescent HRP substrate (Millipore, USA).

\section{Tumorsphere formation assay and in vitro limiting dilution assay}

GICs were plated in 96-well plates at a density of 1,000 cells per well and tumorsphere numbers and sizes were calculated at the seventh day after cell placement. For in vitro limiting dilution assay, GICs were implanted into a 96-well plate at a gradient of 20,40, 60, 80, 100,120 or 140 cells per well, with 10 replicates for each gradient. The number of tumorsphere in each well was determined after incubation for 7 days, and the sphere formation efficiency were calculated using the Extreme Limiting Dilution Analysis (http://bioinf.wehi.edu.au/ software/elda).

\section{Transfection and luciferase reporter assay}

The binding site between RBPJ and CXCR4 promoter was predicted through promo online tool (http://alggen. lsi.upc.es/). Transfection of cells and luciferase assays were performed as described (Picard et al., 2012). Cells were transfected with the pGL3-based constructs containing the CXCR4 promoter plus the Renilla luciferase plasmid (pRL-TK). Then, the cells were harvested after $48 \mathrm{~h}$ for firefly/Renilla luciferase assays using the DualLuciferase Reporter Assay System (Promega). Luciferase activities were normalized to the co-transfected pRL-TK plasmid (mean $\pm \mathrm{SD})$.

\section{Intracranial xenografting of U87GICs}

Animal experiments were approved by the Ethical Committee of Tianjin Medical University General Hospital. U87GICs with scrambled lentivirus and Notch1 shRNA lentivirus were respectively co-infected with a luciferase-expressing lentivirus. Mice were anaesthetized, placed in a stereotactic frame (RWD Life Science, China), and injected with a total of $1 \times 10^{5}$ U87GICs-LUC in $10 \mu \mathrm{l}$ of PBS using a 27-gauge needle at $2 \mathrm{~mm}$ lateral and posterior to the bregma and $3 \mathrm{~mm}$ below the dura. Tumor dimensions were measured every week and animals were sacrificed 5 weeks after inoculation. Cell suspension was injected slowly in $20 \mathrm{~min}$. Then the needle was kept in the injection site for $5 \mathrm{~min}$ before removing it. Tumor cells bioluminescence imaging was performed to assess xenograft formation at 7 days after implantation by using the IVIS Spectrum Live Imaging System.

\section{Statistical analysis}

All quantified data represent an average of at least three experiments unless otherwise indicated, and standard deviations were calculated. All statistical analyses were performed using GraphPad Prism 6.0 (GraphPad Software, La Jolla, CA, USA). Comparisons among groups were performed using unpaired Student's t-tests. Statistical significance was designated as follows: ${ }^{*}: p$ value $<0.05$, $* * p$ value $<0.01, * * * p$ value $<0.001$

\section{Results \\ Increased expression of Notch1 was detected in GBM tissues}

To determine the expression of Notch1 pattern in GBM patients. Firstly, we compared the Notch1 mRNA expression profile across all tumor samples and paired normal tissues in GEPIA (http://gepia.cancer-pku.cn). Compared to other tumors, Notch1 in GBM has a much higher Tumor/Normal tissues ratio (Fig. 1a, b). In Sun Brain and Bredel Brain2 database, Notch1 expression was significantly higher in GBM compared to that in normal brain tissues (NBT) (Fig. 1c, d). Furthermore, immunohistochemical (IHC) staining of Notch1 and Hes1 proteins were performed on 35 paraffin-embedded high grade glioma samples (15 cases anaplastic astrocytoma and 20 cases GBM) and 12 control brain samples. The Notch1 signaling pathway proteins (Notch1, Hes1) were obviously elevated in high grade glioma tissues particularly in GBM tissues (Fig. 1e). Based on this result, we calculated the immunoreactive scores of the different tissue specimens (Fig. 1f and g). Western blot analysis of different grades of glioma tissues also demonstrated that Notch1 is highly expressed in high grade gliomas (WHO III-IV) (Additional file 1: Figure S1a). In addition, the expression profile of Hes1 and its Kaplan-Meier analysis also confirmed this finding (Additional file 2: Figure S2a-e). Meanwhile, a western blot assay was used to measure the Notch1 expression in GBM cell lines, the results revealed that Notch1 was commonly expressed in GBM cell lines (LN-18, SNB-19, U87, U251, LNZ308), highly expressed in the U87, U251 and LN-18 cell lines (Additional file 1: Figure S1b).

\section{Notch1 and CXCR4 are enriched in GICs and co-expressed with stemness markers in GBM tissues}

To determine the relationship between Notch1 and CXCR4 in GBMs, firstly, we detected the expression of CXCR4 proteins in glioma tissues by immunohistochemical staining and western bloting, the results demonstrated that CXCR4 are incresingly expressed in gliomas according to tumor grades and the highest expression levels were detected in GBMs (Additional file 1: Figure S1a and c). Besides, tissue immunofluorescent (IF) staining was performed to observe the distribution of Notch1 signaling molecular and CXCR4 in GBM clinical specimens at a protein level, we found that Nestin (a neural stem cell marker) was expressed in tumor cells adjacent to of the blood micro-vessels labeled by CD31. 
a The gene expression profile across all tumor samples and paired normal tissues.(Dot plot)

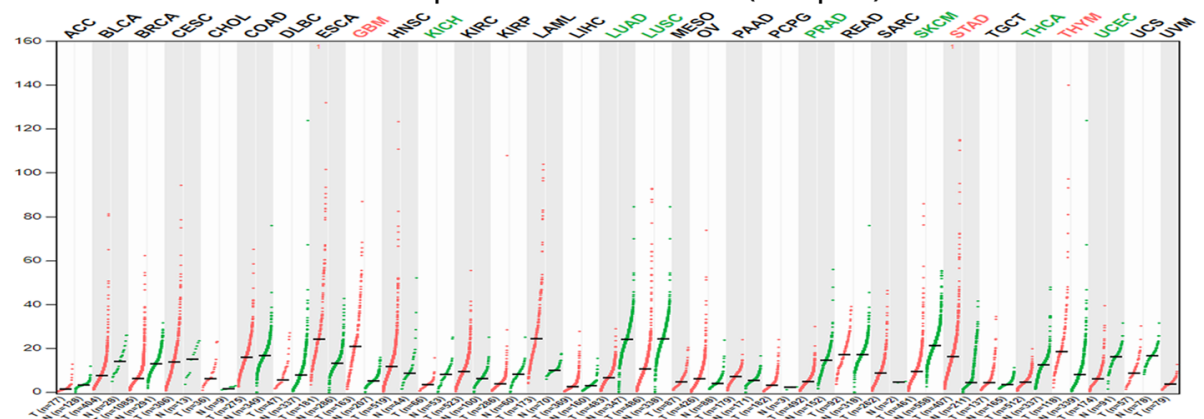

b

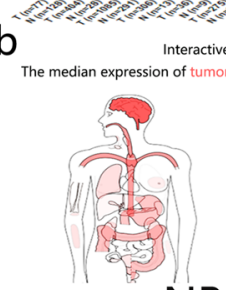

e

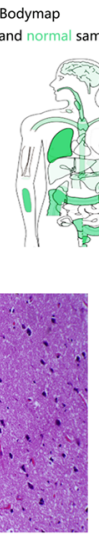

$\mathrm{C}$
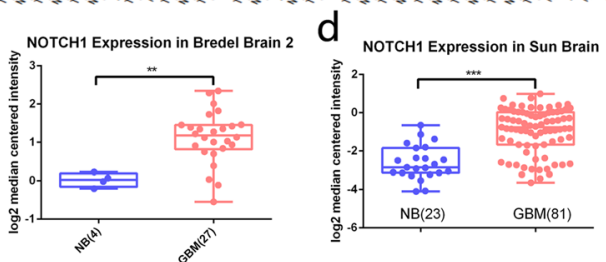

Grade II
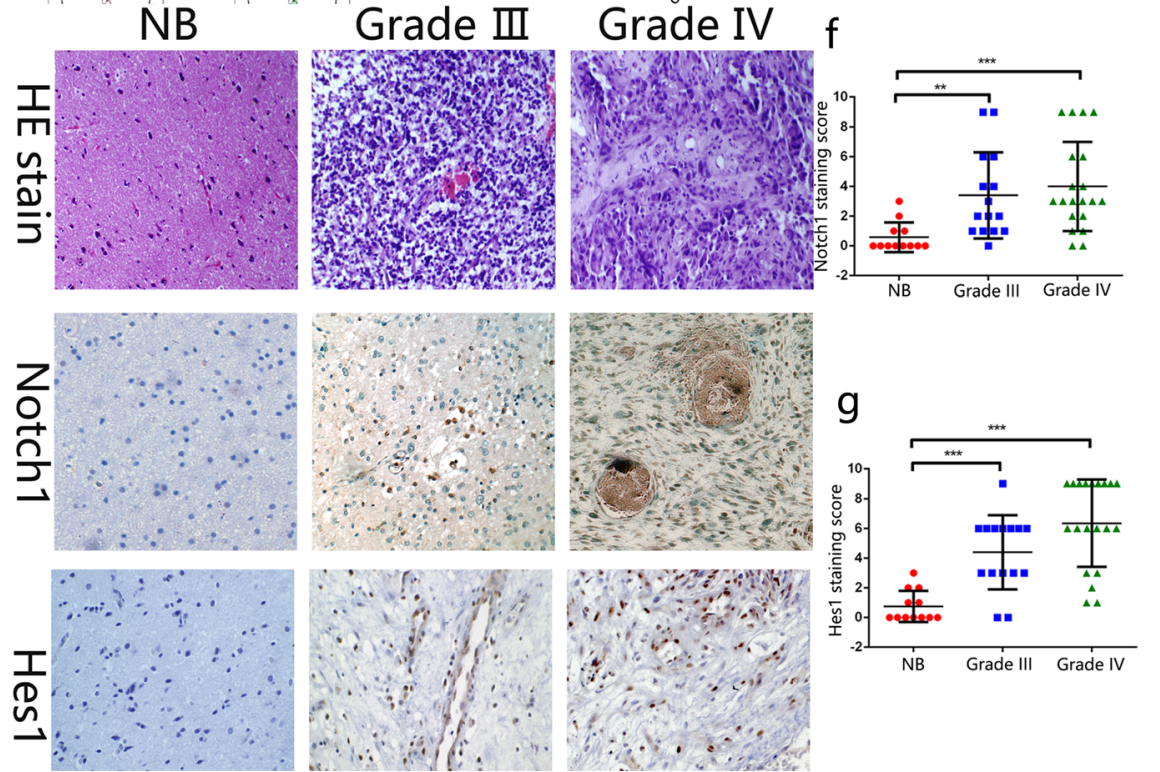

Fig. 1 Notch1 is highly expressed in glioblastoma patients. a and $\mathbf{b}$ Bar plot and interactive bodymap of Notch1 expression levels across all tumor samples. (The extension of tumor abbreviations is available in Additional file 4: Table S1) (c and d) The Notch1 expression in normal brain tissue and GBM across two datasets. $\left.{ }^{*}: P<0.05,{ }^{* *}: P<0.01,{ }^{* * *}: P<0.001\right)$ (e) The Immunohistochemical staining of Notch1 signaling protein (Notch1 and Hes 1 ) in control brain tissues and high grade glioma tissues respectively. (f-g) The quantitative score staining scores were shown. $\left({ }^{*} P<0.05,{ }^{* *} P<0.01,{ }^{* * *} P<0.001\right)$

Furthermore, Notch1, Hes1 and CXCR4 expressing cells colocalized with or adjacent to the Nestin expressing glioma cells. CXCR4 and Notch1 are also colocalized in same cells within GBM tissue. (Fig. 2a). Then, we retrieved data (NCBI GEO dataset: GSE23806) on the expression of Notch1 signaling molecular and CXCR4 in 36 conventional cell lines, 27 glioma stem like cell lines and 17 glioblastoma derived neurospheres. We compared the expression of the interest pathway molecules in the cell lines and found that the expression of Notch1 signaling genes and CXCR4 was significantly higher in glioma stem like cells and neurospheres than in conventional cell lines (Fig. 2b). Moreover, we examined Notch1 and CXCR4 with stemness markers in GSE23806 dataset using Pearson correlation assay (Fig. 2c-d). Both Notch1 and CXCR4 showed high correlation with stemness markers among GBM cell lines, suggesting synergistic effects in stem maintenance. 


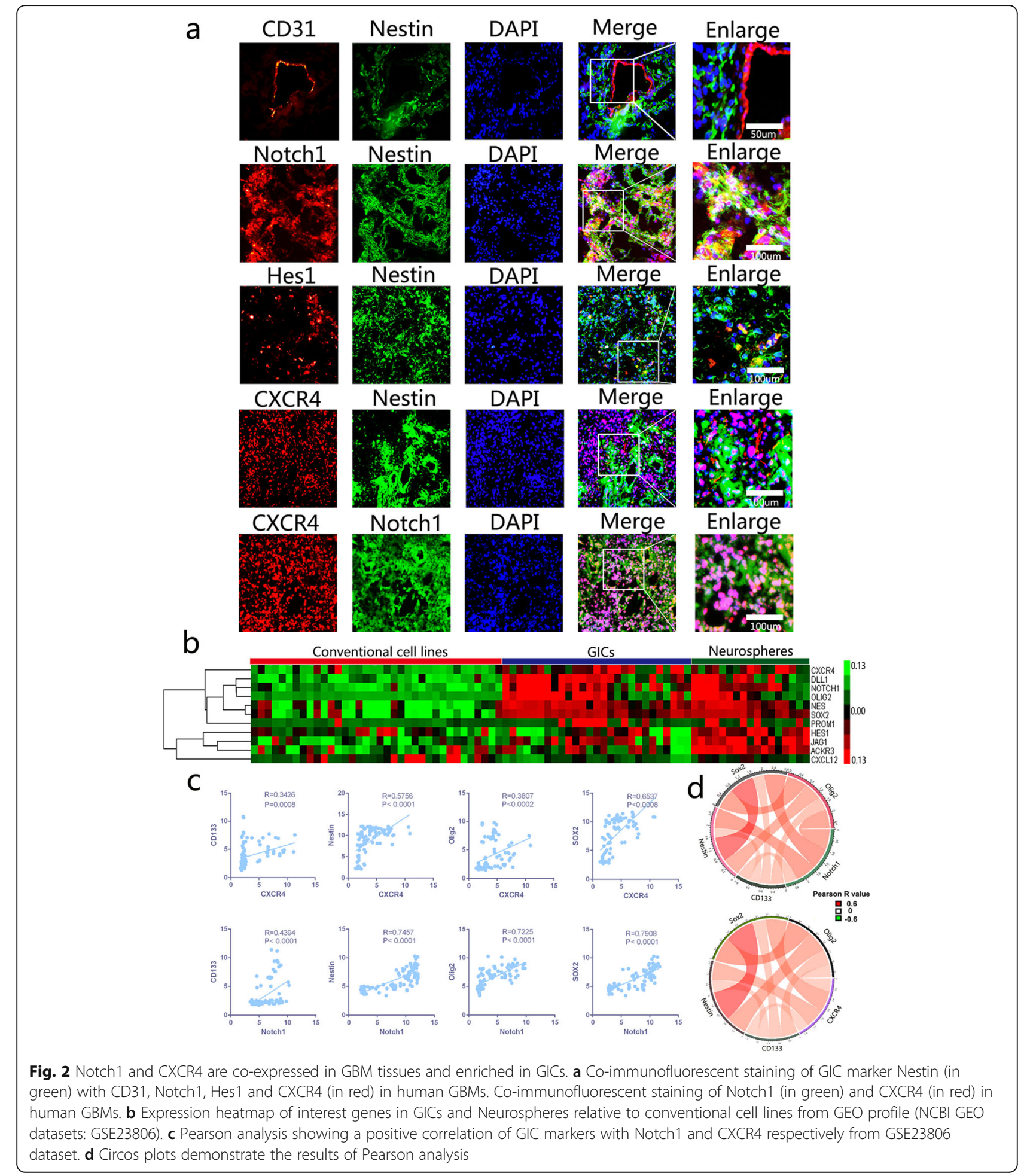

Notch1 and CXCR4 presented a discrepant expression pattern in GICs

To study the regulatory mechanism of the Notch1 pathway and CXCR4 in GICs, we applied Magnetic Activated Cell Sorting (MACS) to enrich CD133+ cells from U87 and U251 glioma cells, both CD133 and Nestin were stained to assess the stem cell phenotype, CD133 positive cells exhibited a high Notch1 activity (Fig. 3a). Not quietly consistent with our speculation, confocal microscopy immunofluorescence of glioma tumorsphere displayed that contrasting to Notch1 positive glioma cells which comprised a large proportion in the CD133+ glioma cell 


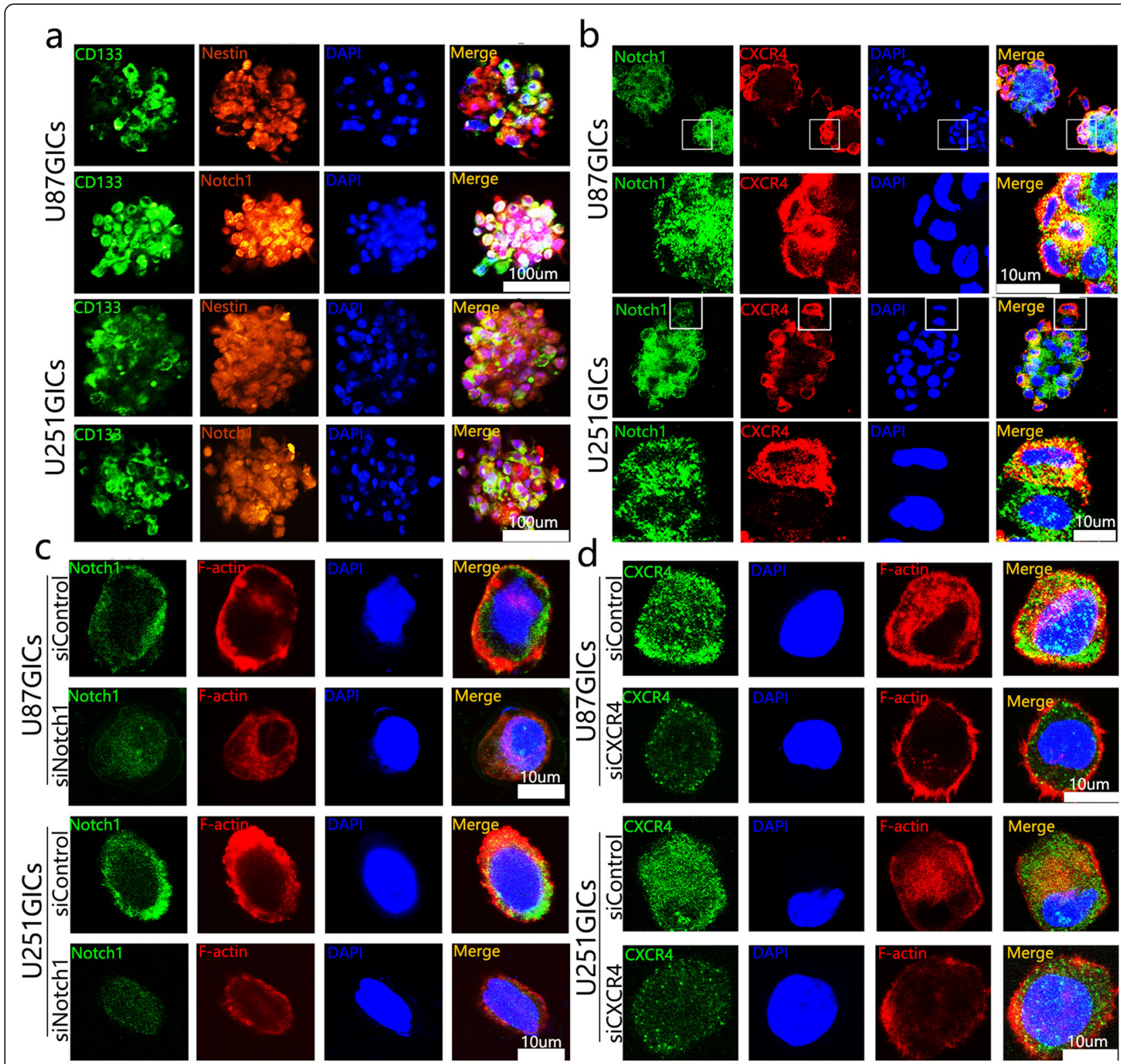

Fig. 3 Notch1 and CXCR4 presented discrepant expression patterns in GICs. a Co-immunofluorescent staining of CD133 and Nestin was performed to assess GIC phenotype, CD133 and Notch1 staining was used to identify Notch1 signaling activity in GIC tumorspheres. b Co-immunofluorescent staining of Notch1 and CXCR4 in GIC tumorspheres. c Co-immunofluorescent staining of Notch1 and F-actin d CXCR4 and F-actin. Images were captured by laser confocal microscope

spheres, CXCR4 positive glioma cells only represent a small subset of CD133+ glioma cell spheres. Interestingly, these CXCR4 positive glioma cell, usually expressed Notch1 both and dispersed in the periphery of the sphere (Fig. 3b). Furthermore, U87/U251 GICs transfected with siControl and siCXCR4 were subjected to F-actin staining. We observed that the CXCR4 protein was almost colocalized with F-actin, meanwhile, the decreased CXCR4 expression paralleled with a weaker microfilament staining (Fig. 3d). However, these phenomena were not observed in siControl and siNotch1 U87 and U251 GICs (Fig. 3c).
As the cytoskeleton F-actin was considered to be bounded up with various cancer biology mainly includes cell migration and invasion as well as in self-renewal [7, 26, 27], CXCR4 might exert a crucial role in stem maintenance and migration of GICs.

Notch1 contributes to the invasion, migration and selfrenewal of GICs by CXCL12/CXCR4 system

The presence of GICs has been reported in the U87 and U251 cell [28] lines as well as the fact that Notch1 could maintain glioma cell stemness $[7,29,30]$. To investigate 
the mechanisms underlying Notch1 regulation of GICs invasion and self-renewal, stable Notch1-knockdown glioma initiation cells (U87-shNotch1 and U251-shNotch1) were established (Additional file 3: Figure S3a-b) and western blot showed that inhibition of Notch1 pathway through shRNA or MK0752 in U87 and U251 derived GICs could quantitatively decrease the expression of CXCR4, but the expression of CXCL12 made no difference in the shNC and shNotch1 groups (Additional file 3: Figure S3c-d). To examine the effects of Notch1 on the self-renewal properties of GICs, tumorsphere formation and limiting dilution assay was performed. We observed a significant decreased volume and a higher number of cells required to generate tumor sphere in shNotch1 group while the additional $100 \mathrm{ng} / \mathrm{ml}$ of CXCL12 could significantly rescue this trend and boost the self-renewal ability of GICs (Fig. 4a-c). To investigate the effects of Notch1 on invasion and migration ability in GICs, Transwell invasion and migration assays was performed and revealed that downregulation of Notch1 could significantly restrained both migration and invasion in U87GICs and U251GICs. Moreover, addition of CXCL12 $(100 \mathrm{ng} / \mathrm{ml})$ partly rescued downregulation of Notch1 mediated cell migration and invasion restriction (Fig. 4d-g). Those results demonstrate that Notch1 contributes to the invasion, migration and self-renewal of GICs through CXCL12/CXCR4 system.

\section{Notch1 potentiates the AKT/m-TOR pathway and CXCL12/ CXCR4 axis in GICs}

It has been reported that activating the Notch1/Hes1 pathway could accelerate cell invasion, migration and proliferation through the $\mathrm{PI} 3 \mathrm{k} / \mathrm{AKT} / \mathrm{mTOR}$ pathway in acute $\mathrm{T}$ lymphocyte leukaemia and mesothelioma $[31,32]$. The Notch pathway has also been found to promote ovarian cancer growth and migration via the CXCL12/CXCR4 chemokine system [33]. However, in GICs, the exact mechanism has not been elucidated. MK-0752 is a potent $\gamma$-secretase inhibitor (GSI), which could block the Notch intracellular domain (NICD) and the expression of Hes1. To further confirm that Notch1 promotes invasion and self-renewal and tumor growth by potentiating the AKT pathway, MK0752 was used to inhibit the Notch1 pathway. To determine the optimal concentration of MK0752, U87GICs were treated with different concentrations of MK0752 $(0,10,20,40,80$, $100,150 \mathrm{nM}$ ) for $48 \mathrm{~h}$, respectively. The results showed that MK0752 treatment reduced the protein expression of activated Notch1 (NICD) in a dose-dependent manner (Additional file 3: Figure S3e). Due to no significant differences between the 80 and $100 \mathrm{nM}$ of MK0752 treatments via western blot, $80 \mathrm{nM}$ of $\mathrm{MK} 0752$ was used in the subsequent experiments. The Notch1 pathway was downregulated with shRNA or MK0752 among U87GICs and U251GICs. The expression of CXCR4 and the phosphorylation levels of AKT and mTOR were significantly inhibited (Fig. 5a-d).

\section{Blockage of Notch1 attenuates AKT/mTOR signaling activity by CXCL12/CXCR4 system}

CXCL12 is a specific ligand for CXCR4, to demonstrate that CXCR4 is a mediator between Notch1 and the AKT/mTOR pathway, $100 \mathrm{ng} / \mathrm{ml} \mathrm{CXCL12} \mathrm{was} \mathrm{used} \mathrm{to}$ stimulate CXCR4 after incubation for $30 \mathrm{~min}$ [34]. As expected, CXCL12 significantly increased AKT and mTOR phosphorylation in GICs compared to that in the cells without CXCL12 treatment. Interestingly, in the Notch1 downregulated GICs, treatment with CXCL12 resulted in no remarkable decrease in the phosphorylation of AKT/mTOR (Fig. 6a-d), which indicated that CXCL12 may reverse the downregulation of AKT/ mTOR phosphorylation induced by shNotch1 and revealed that the CXCL12/CXCR4 axis is upstream of the $\mathrm{AKT} / \mathrm{mTOR}$. We further investigated the regulatory mechanism underlying the correlation between Notch1 and CXCR4 by dual-luciferase reporter assays, RBPJ, the downstream transcription factor of Notch1 signaling was proposed to bind to the region of the CXCR4 using PROMO tool (Fig. 6e). Our results indicated that inhibition of Notch1 signaling or mutated RBPJ binding area of CXCR4 promoter could significantly reduce the CXCR4 promoter activity in U87 and U251GICs (Fig. $6 \mathrm{~g}$ and h), suggesting that RBPJ directly binds to the CXCR4 promoter to control its transcription thus modulating AKT/ mTOR activity (Fig. 6f).

\section{Silencing of Notch1 inhibits tumor growth and invasion in vivo}

To investigate the influence of Notch1 expression on tumor growth in vivo, we performed experiments according to the schematic diagram (Fig. 7a). We observed shRNA-NC or shRNA-Notch1 GICs in mouse brains in vivo by living imaging which showed increasing radiance values corresponding to increasing tumor growth. We found that the radiance values were lower in shNotch1 tumors compared with control group (Fig. 7b). Furthermore, the hematoxylin and eosin (HE) stained intracranial tumors also showed smoother tumor borders in the shNotch1 groups (Fig. 7f). Likewise, Notch1 downregulation was associated with a longer survival (Fig. 7d) and a decreased weight loss in mice (Fig. 7c). In addition, Immunohistochemistry (IHC) displayed decreased expression levels of Notch1, CXCR4 and pAKT in shNotch1 group, the result consistent with in vitro experiments (Fig. 7e). 
a
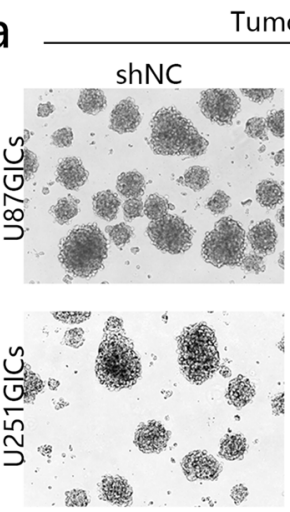

umorsphere formation assay
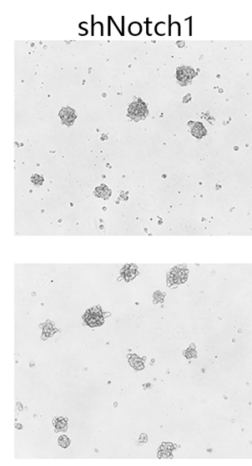
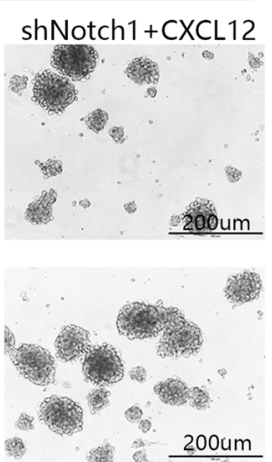
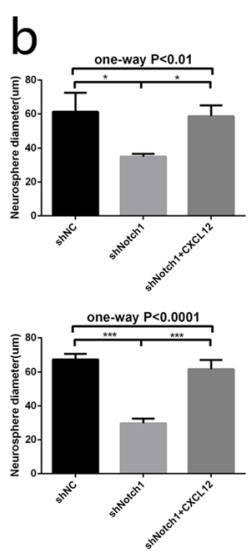

C invitro limiting dilution assay
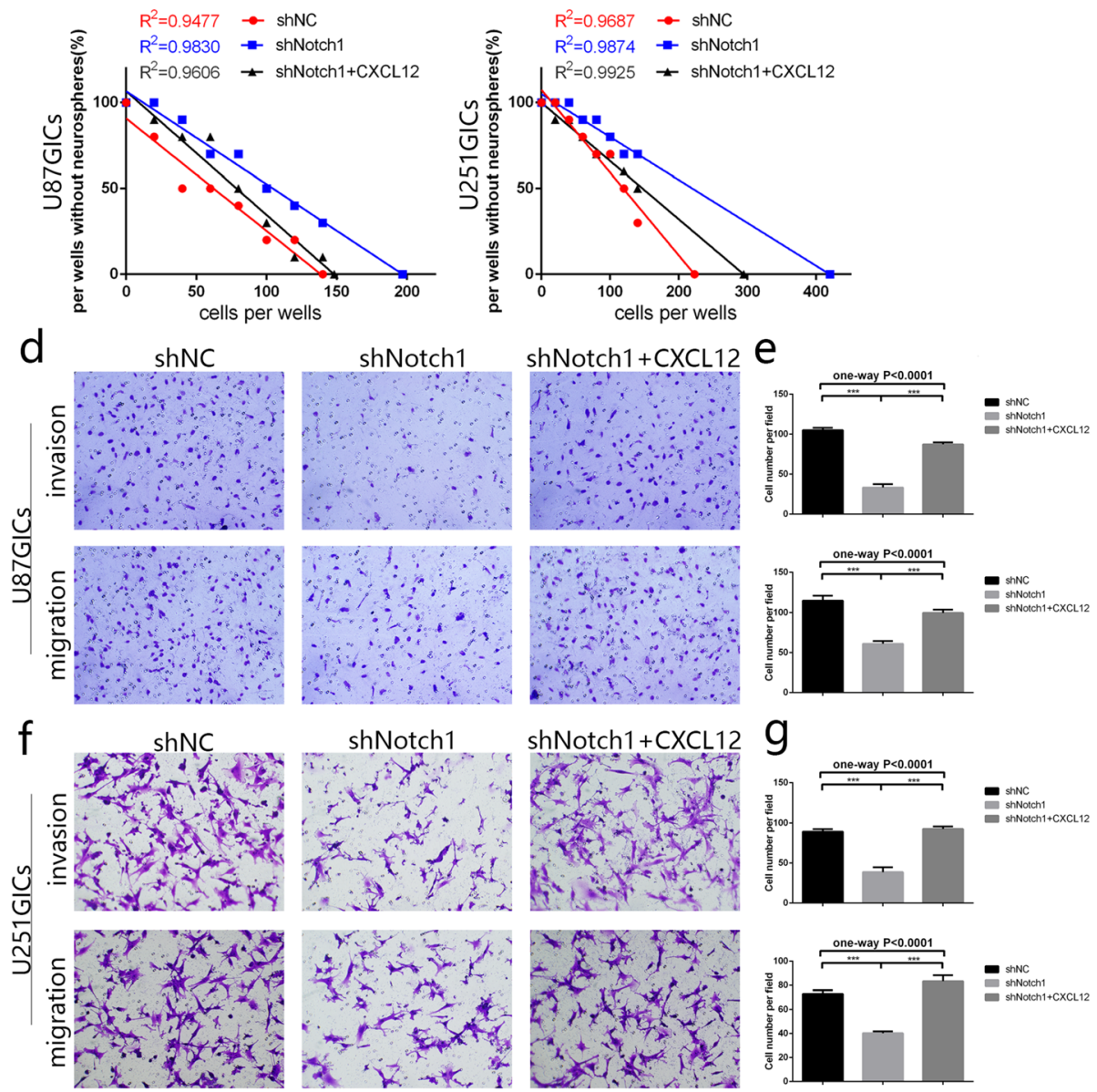

shNotch1+CXCL12 9
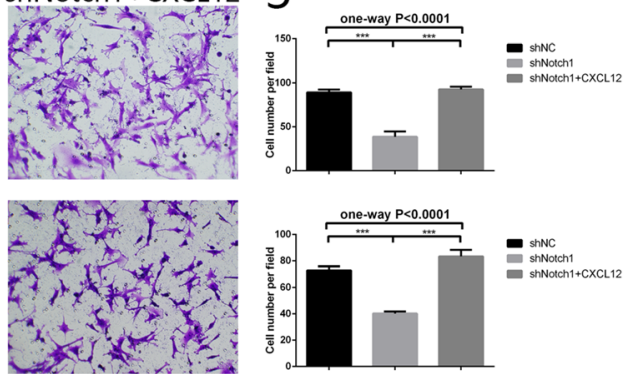

Fig. 4 Notch1 is required for invasion, migration properties and self-renewal of GICs by CXCL12/CXCR4 system. a-b Morphology of tumor spheres formed by the cancer initiating cells from U87 and U251 glioma cells. And Quantitative analysis were shown respectively. c In vitro limiting dilution assay of U87GICs and U251GICs in negative control, shRNA-Notch1 and shNotch1 + CXCL12 groups. d-g Transwell assay of U87GICs and U251GICs in negative control, shRNA-Notch1 and shNotch1 + CXCL12 groups. And Quantitative analysis were shown respectively. ${ }^{*} P<0.05$, $\left.{ }^{* *} P<0.01,{ }^{* * *} P<0.001\right)$

\section{Discussion}

As early as 2006, Androutsellis-Theotokis et al. demonstrated that Notch signaling could regulate stem cell numbers in vitro and in vivo [35]. Since then, numerous studies have been carried out. Up to now, Notch signaling has been found to be involved in many cell fate decisions such as cell proliferation, differentiation and apoptosis during normal development and in the genesis of several 


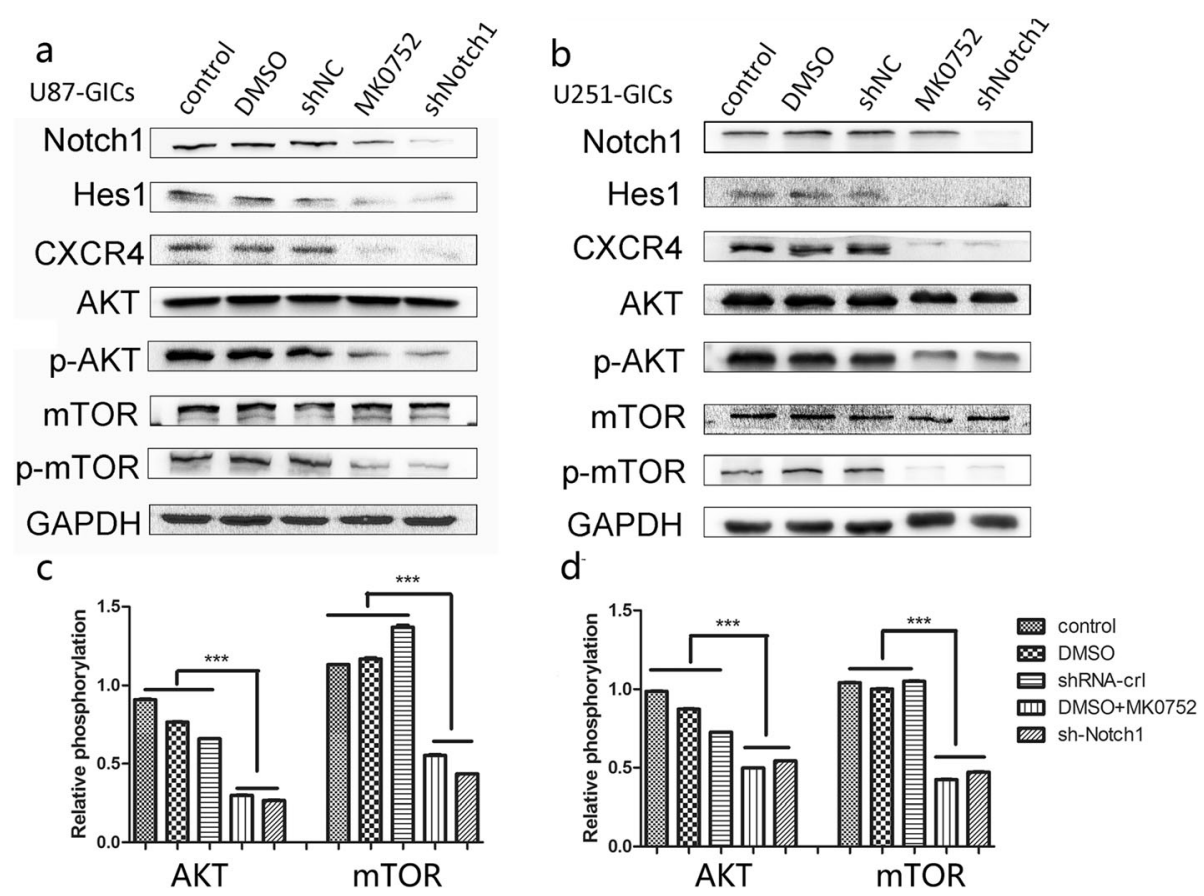

Fig. 5 Notch1 enhance the activity of AKT/mTOR pathway and CXCL12/CXCR4 axis. a-b Decreased protein level of Hes1 (Notch1 pathway downstream factors), CXCR4, p-AKT and p-mTOR were measured by western blot after blockage of Notch1 signaling by shRNA-Notch1 and MK0752 in U87GICs and U251GICs. c-d The relative phosphorylation of AKT and mTOR were shown respectively. ${ }^{*} P<0.05$, $\left.{ }^{*} P<0.01,{ }^{* * *} P<0.001\right)$

cancers. Most recently, several studies have reported that Notch was enriched in CSCs and has been shown to maintain the stem cell phenotype [7, 36]. In gliomas, Notch seems to confer radio-resistance to cancer stem cells [11], and inhibition of Notch signaling through $\gamma$ secretase inhibitors could decreased the tumor neurospheres growth [35], glioblastoma xenograft initiation and clonogenic growth in vivo [37]. Although Notch1 plays a vital role in a variety of tumors, most of the clinical trials of Notch1 have showed modest efficacy and only in the initial stage, it is probably due to the complex heterogeneity of glioma and the crosstalk between Notch pathway and other molecules. Consequently, it is urgent to understand the mechanism of Notch regulation of tumorigenesis in GICs. Many studies have shown that Notch1 can regulate $\mathrm{PI} 3 \mathrm{~K} / \mathrm{AKT} / \mathrm{mTOR}$ pathway activity. In T-cell acute lymphoblastic leukemia (T-ALL), Teresa et al. revealed that Hes1 could decrease the protein level of PTEN and enhance the activity of the PI3K/AKT/mTOR pathway [38]. Shepherd et al. found that drugs targeting PI3K/ mTOR can upregulate NOTCH-MYC activity leading to a cytotoxic response [39]. In addition to PTEN, the Notch pathway also regulates PI3K/AKT/mTOR pathway activity via P53 and EGFR [40, 41]. However, the biological behavior and related molecular mechanism of Notch1 in glioma initiating cells are not well reported worldwide.
A growing number of studies have found that CXCR4 is more likely present within the glioma stem like cell population compared with differentiated glioma cells. It is increasingly expressed in glioma cells corresponding to increasing tumor grade [42]. There have been various reports suggesting that CXCR4 is required for tumor proliferation, invasion, angiogenesis, and modulation of the immune response [14]. It may also serve as a prognostic factor in characterizing subsets of glioblastoma multiforme [42], as patients with CXCR4-positive gliomas seem to have a worse prognosis after surgery and is associated with an angiogenic switch in recurrence of glioblastoma after radiochemotherapy [43, 44]. Ping et al. [34] found that compared with CD133- cells, CD133+ GSCs expressed significantly higher levels of CXCR4, and migrated more efficiently in response to the CXCR4 ligand CXCL12. Liang [45] reported that the SDF-1/CXCR4 axis can promote the phosphorylation of AKT and then increase the expression of VEGF and promote angiogenesis in breast cancer. The few studies that have looked into the role of CXCR4 in Notch1 signaling among several types of cells. In mesenchymal stem cells, for example, mRNA levels of CXCR4 were significantly increased when Notch signaling was interrupted by c-secretase inhibitor (GSI) or knockout of the transcription factor RBP-J [46]. But the same 
a

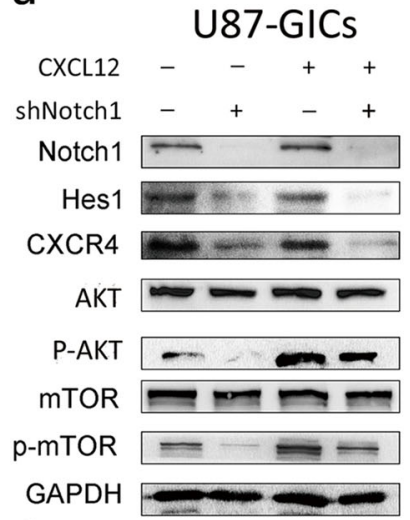

$C$

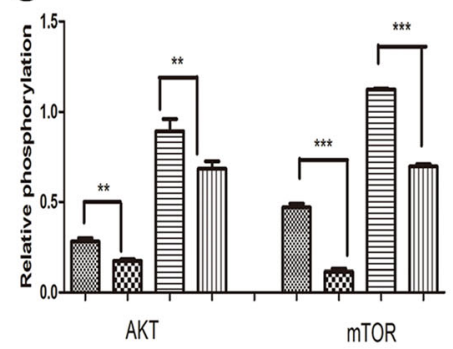

b
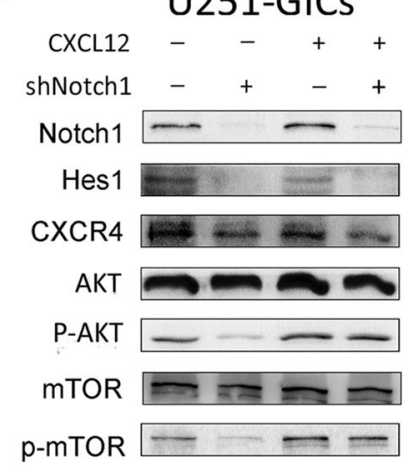

GAPDH

d

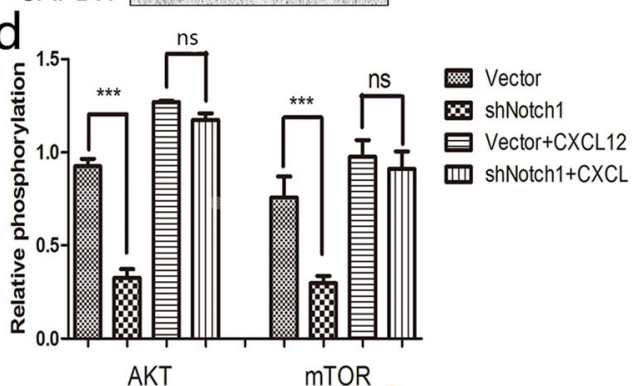

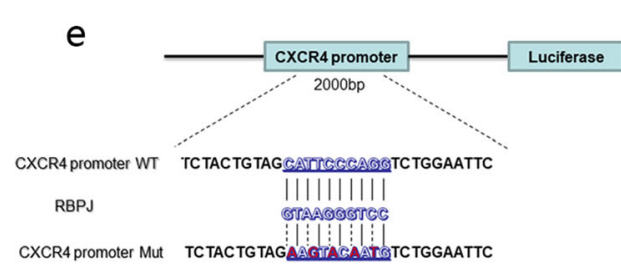

f Notch1

g

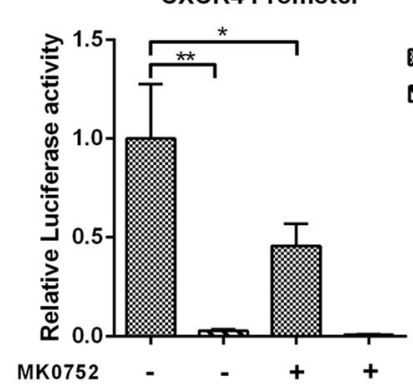

h

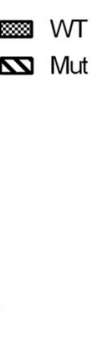

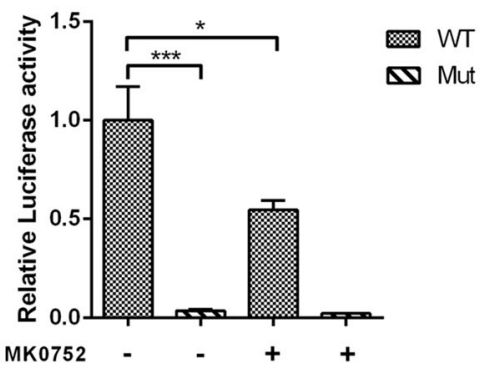

Fig. 6 Notch1 enhance the activity of AKT/mTOR pathway through CXCL12 /CXCR4 axis. a and $\mathbf{c}$ The representative blot and relative phosphorylation of AKT and mTOR in U87GICs were shown. $\mathbf{b}$ and $\mathbf{d}$ The representative blot and relative phosphorylation of AKT and mTOR in U251GICs were shown. ${ }^{*} P<0.05,{ }^{*} P<0.01,{ }^{* *} P<0.001$, ns: no significance) e Schematic representation of the potential binding sites for RBPJ in CXCR4 promoter. and mutant type of luciferase reporter constructs have intact and mutated seed sequences. $\mathbf{g}$ and $\mathbf{h}$ Dual-reporter luciferase assays showed the relative luciferase activity of WT and Mut reporter constructs as well as Notch1 inhibition (MK0752) group. f Proposed model illustrates the underlying crosstalk between Notch1 and CXCR4 in GICs through PI3K/AKT/mTOR pathway. Notch1 signaling could interact with CXCL12/CXCR4 Chemotaxis system by directly regulating CXCR4's promoter

treatment, down-regulates CXCR4 expression in ovarian cancer [33], suggesting complicated relationship between Notch signaling and the CXCR4 expression.

In this study, we provide evidence that Notch1 signaling is highly activated in GBM tissues and its target gene Hes1 is correlated with poor patient survival. Moreover, our results showed that Notch1 signaling and CXCR4 were highly correlated in GBM tissues and enriched in GICs. However, in GICs, Notch1 and CXCR4 presented a discrepant expression 


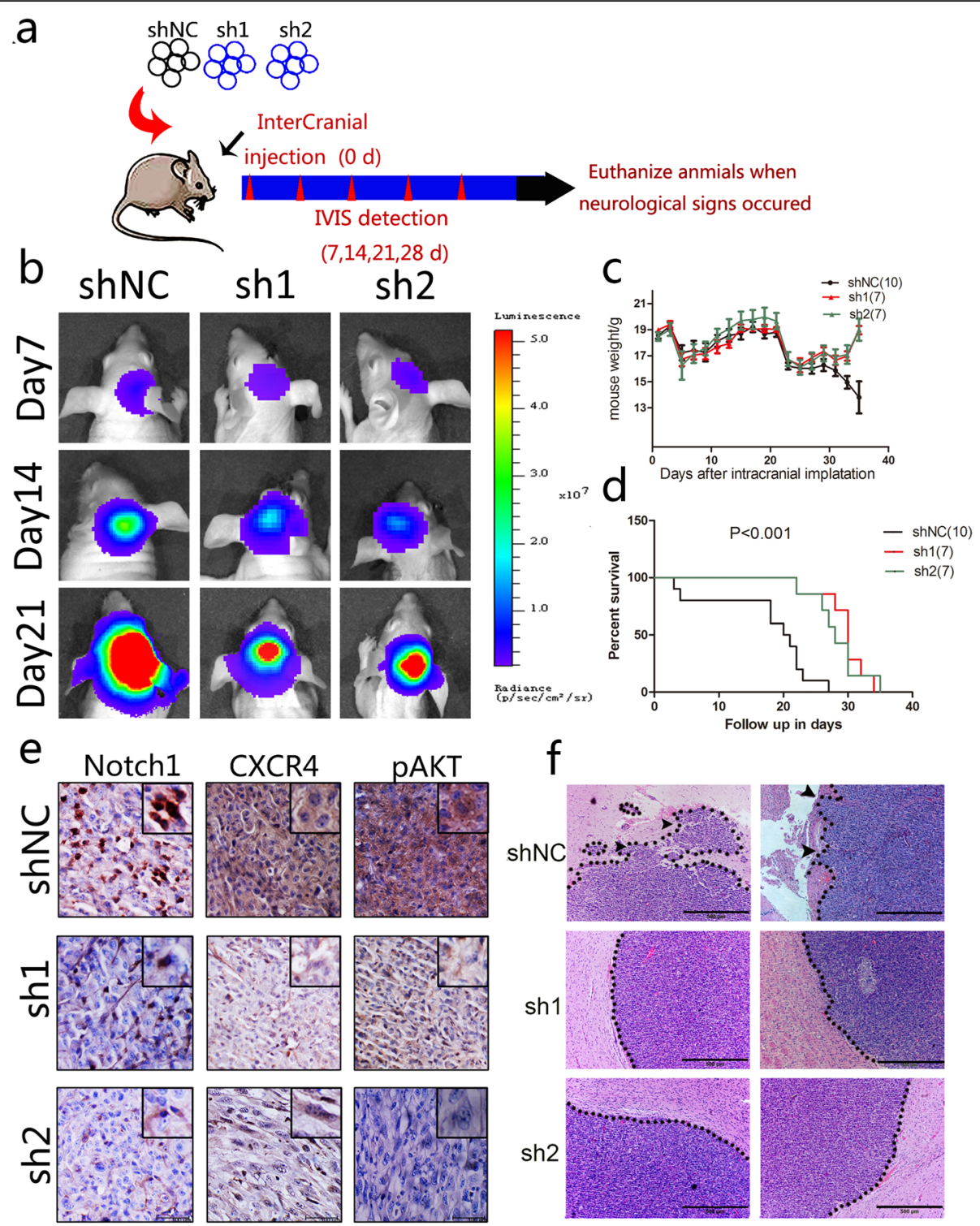

Fig. 7 Silencing of Notch1 inhibits tumor growth and invasion in vivo. a Schematic diagram of Intracranial implantation of U87-GICs expressing shNotch1 or shNC. $\mathbf{b}$ The representative bioluminescent images of the tumor-bearing mice implanted with U87-GICs. c Mouse weight was recorded as a measure of mouse nutrition in the two groups. $\mathbf{d}$ Kaplan-Meier survival curve was used to detect differences in mouse survival times between the two groups. e Immunohistochemistry analysis of the expression of Notch1, CXCR4 and pAKT in Notch1-shRNA treated tumors compared to tumors in the shNC group. $\mathbf{f}$ Representative images of H\&E staining of tumor border from mice 3 weeks after tumor implantation (black triangle: disseminated tumors)

pattern. As the CXCR4 positive glioma initiating cells co-expressed with Notch1 usually dispersed in the periphery of the tumorsphere, we put forward the hypothesis that CXCR4 might exert a crucial role in the Notch1 signaling mediated stem maintenance and migration of GICs. Subsequently, our study demonstrated that Notch1 downregulation could significantly inhibit glioma initiating cell biological behavior including self-renewal invasion and migration in vitro, as well as tumor growth in vivo. Furthermore, western blot analysis and luciferase reporter assay were employed to clarify the potential mechanism involved in Notch1 regulated GICs, we found that CXCL12 / CXCR4 acted as a central node between Notch1 signaling and AKT/mTOR pathway. Notch1 signaling could modulate CXCR4 through directly targeting its promoter (Fig. 8).

\section{Conclusions}

Our findings provide direct evidence that Notch1 pathway promotes GIC self-renewal, invasion and tumor growth through PI3K pathway activity via upregulating CXCR4 expression. Furthermore, the CXCL12/CXCR4 


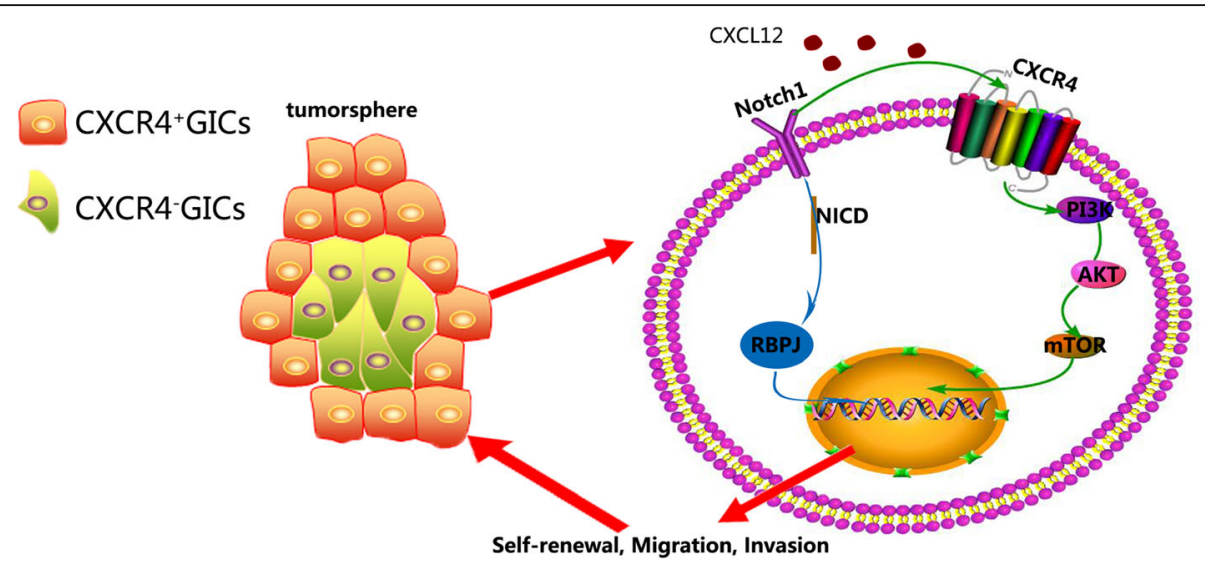

Fig. 8 Model of the mechanism of Notch1 signaling and CXCL12/CXCR4 axis in GICs self-renewal, invasion and tumor growth. CXCR4 positive glioma cells, usually expressed Notch1 both and dispersed in the periphery of the tumorsphere. Notch1 signaling promotes the self-renewal, invasion and tumor growth of glioma initiating cells via AKT/mTOR pathway activity medicated by CXCL12/CXCR4 axis

axis is an important immediate effector of Notch1 that mediates downstream mechanisms. All of these findings would facilitate the development of molecular therapies targeting the Notch1 signaling pathway for GBM management.

\section{Additional files}

Additional file 1: Figure S1. The expression pattern of Notch1 and CXCR4 in glioma tissues and cell lines. (a) The protein expression of Notch1 and CXCR4 in different grade glioma tissues. (b) The expression of Notch1 in GBM cell lines. (c) The expression of CXCR4 and CXCL12 in high grade glioma tissues through immunohistochemistry analysis. (TIF $7560 \mathrm{~kb}$ )

Additional file 2: Figure S2. The expression of Hes 1 and its association with patient's prognosis. (a-c) Accordingly, in contrast to NBT or lowgrade astrocytoma, Hes1 (Notch1 targeting gene) was notably upregulated in GBM patients according to TCGA, Sun Brain and French's datasets. (d) Kaplan-Meier analysis of overall survival probability for the TCGA database with the log rank test $P$ value was indicated. (e) Kaplan-Meier analysis of overall survival probability for the CGGA database with the log rank test $P$ value indicated. (TIF $4670 \mathrm{~kb}$ )

Additional file 3: Figure S3. Downregulation of Notch1 signaling through pharmacological intervention and RNA interference. (a) Knockdown of Notch1 in two RNA interference sequence, and the shRNA with a better effect was used in the invitro study. (b)Western blot assay was used to characterize the expression of Notch1 signaling protein in shNotch1 U87GICs and U251GICs. (c) Reduction of NICD and CXCR4 in GICs induced by MK0752 in a dose-dependent fashion. (d) The expression of CXCL12 /CXCR4 system in the shNC and shNotch1 groups. (e) Reduction of NICD in GICs induced by MK0752 in a dose-dependent fashion (due to no significant differences in NICD expression between 80 and $100 \mathrm{nM}$ of MK0752 treatment, $80 \mathrm{nM}$ of MK0752 was used in the western blot assay). (TIF $3290 \mathrm{~kb}$ )

Additional file 4: Table S1. The extension of tumor abbreviations. (DOCX $17 \mathrm{~kb})$ (TIF $9945 \mathrm{~kb})$

\section{Abbreviation}

CCLs: Conventional cell lines; ECM: Extracellular matrix; GBM: Glioblastoma multiforme; GICs: Glioma initiating cells; GSCs: Glioma stem cells; GSI: үSecretase inhibitor; GSLCs: Glioblastoma stem-like cell lines; HGG: High grade glioma; IF: Immunofluorescence; MACS: Magnetic activated cell sorting; NBT: Normal brain tissues; NICD: Notch intracellular domain;
SDF1: Chemokine stromal cell-derived factor 1; SFM: Serum-free medium; TALL: T-cell acute lymphoblastic leukaemia

Acknowledgments

Not applicable.

\section{Authors' contributions}

$L Y, X C Z$ and $T L$ performed the experiments, LY performed data analysis and drafted the manuscript. LY and XCZ participated in the design of this study. $\mathrm{LH}$ and $\mathrm{TL}$ contributed to the design of this study, XJY managed the experimental design, reviewed the manuscript and provided funding support. All authors have read and approved the final manuscript.

\section{Funding}

The research is funded by the National Natural Science Foundation of China (No. 81872063 and No. 81472352).

\section{Availability of data and materials}

All data and materials can be provided upon request.

\section{Ethics approval and consent to participate}

All patients signed and approved consent forms prior to the surgery and human tissues study was approved by the Ethics Committee of Tianjin Medical University Hospital (Tianjin, China). The use of animals in this study was approved by the Ethics Committee in Tianjin Medical University General Hospital.

\section{Consent for publication}

Not applicable.

\section{Competing interests}

The authors declare that they have no competing interests.

\section{Author details}

'Department of Neurosurgery, Tianjin Medical University General Hospital, Tianjin 300052, China. ${ }^{2}$ Laboratory of Neuro-Oncology, Tianjin Neurological Institute, Tianjin 300052, China. ${ }^{3}$ Department of Neurosurgery, The Second Affiliated Hospital of Bengbu Medical College, Anhui 233000, China. ${ }^{4}$ Department of Radiation Oncology, Henan Cancer Hospital, The Affiliated Cancer Hospital of Zhengzhou University, Henan 450000, China.

${ }^{5}$ Neuro-Oncology Department, The University of Texas MD Anderson Cancer Center, Houston 77030, Texas, USA. 


\section{Received: 6 March 2019 Accepted: 10 July 2019}

\section{Published online: 05 August 2019}

\section{References}

1. Ostrom QT, Gittleman H, Xu J, Kromer C, Wolinsky Y, Kruchko C, BarnholtzSloan JS. CBTRUS statistical report: primary brain and other central nervous system tumors diagnosed in the United States in 2009-2013. Neurooncology. 2016;18:v1-v75.

2. Chinot OL, Wick W, Mason W, Henriksson R, Saran F, Nishikawa R, Carpentier AF, Hoangxuan K, Kavan P, Cernea D. Bevacizumab plus radiotherapy-Temozolomide for newly diagnosed glioblastoma. N Engl J Med. 2014;370:709-22.

3. Lathia JD, Mack SC, Mulkearns-Hubert EE, Valentim CL, Rich JN. Cancer stem cells in glioblastoma. Genes Dev. 2015;29:1203-17.

4. Filatova A, Acker T, Garvalov BK. The cancer stem cell niche(s): the crosstalk between glioma stem cells and their microenvironment. Biochim Biophys Acta. 2013;1830:2496

5. Lathia JD, Heddleston JM, Venere M, Rich JN. Deadly teamwork: neura Cancer stem cells and the tumor microenvironment. Cell Stem Cell. 2011;8:482-5.

6. Schonberg DL, Lubelski D, Miller TE, Rich JN. Brain tumor stem cells: molecular characteristics and their impact on therapy. Mol Asp Med. 2014; 39:82-101.

7. Chen Z, Long H, Meng Z, Yu S, Tao L, Yu L, Bo L, Zhou X, Lei C, Zhao P. Actin cytoskeleton regulator Arp2/3 complex is required for DLL1 activating Notch1 signaling to maintain the stem cell phenotype of glioma initiating cells. Oncotarget. 2017:8:33353-64.

8. Fan X, Matsui W, Khaki L, Stearns D, Chun J, Li YM, Eberhart CG. Notch pathway inhibition depletes stem-like cells and blocks engraftment in embryonal brain tumors. Cancer Res. 2006;66:7445-52.

9. Purow BW, Haque RM, Noel MW, Su Q, Burdick MJ, Lee J, Sundaresan T, Pastorino S, Park JK, Mikolaenko I. Expression of Notch-1 and its ligands, Delta-like-1 and Jagged-1, is critical for glioma cell survival and proliferation. Cancer Res. 2005;65:2353.

10. Takebe N, Harris PJ, Warren RQ, Ivy SP. Targeting cancer stem cells by inhibiting Wnt, Notch, and hedgehog pathways. Nat Rev Clin Oncol. 2010;1:97

11. Wang J, Wakeman TP, Lathia JD, Hjelmeland AB, Wang XF, White RR, Rich $\mathrm{JN}$, Sullenger BA. Notch promotes radioresistance of glioma stem cells. Stem Cells. 2010;28:17-28.

12. Xu R, Shimizu F, Hovinga K, Beal K, Karimi S, Droms LA, Peck KK, Gutin P, lorgulescu JB, Kaley TJ. Molecular and clinical effects of Notch inhibition in glioma patients: a phase 0/I trial. Clin Cancer Res. 2016;22:4786.

13. Pannuti A, Foreman K, Rizzo P, Osipo C, Golde T, Osborne B, Miele L. Targeting Notch to target cancer stem cells. Clin Cancer Res. 2010;16: 3141-52.

14. Gagliardi F, Narayanan A, Reni M, Franzin A, Mazza E, Boari N, Bailo M, Zordan P, Mortini P. The role of CXCR4 in highly malignant human gliomas biology: current knowledge and future directions. Glia. 2014;62:1015-23.

15. Mukherjee D, Zhao J. The role of chemokine receptor CXCR4 in breast cancer metastasis. Am J Cancer Res. 2013;3:46-57.

16. Guo F, Wang Y, Liu J, Mok SC, Xue F, Zhang W. CXCL12/CXCR4: a symbiotic bridge linking cancer cells and their stromal neighbors in oncogenic communication networks. Oncogene. 2016;35:816.

17. Rubin JB, Kung AL, Klein RS, Chan JA, Sun Y, Schmidt K, Kieran MW, Luster $A D$, Segal RA. A small-molecule antagonist of CXCR4 inhibits intracranial growth of primary brain tumors. Proc Natl Acad Sci U S A. 2003;100:13513.

18. Hermann PC, Huber SL, Herrler T, Aicher A, Ellwart JW, Guba M, Bruns CJ, Heeschen C. Distinct populations of cancer stem cells determine tumor growth and metastatic activity in human pancreatic cancer. Cell Stem Cell. 2007;1:313-23

19. Miki J, Furusato B, Li H, Gu Y, Takahashi H, Egawa S, Sesterhenn IA, Mcleod DG, Srivastava S, Rhim JS. Identification of putative stem cell markers, CD133 and CXCR4, in hTERT-immortalized primary nonmalignant and malignant tumor-derived human prostate epithelial cell lines and in prostate Cancer specimens. Cancer Res. 2007;67:3153-61.

20. Xuesheng Z, Qingsong X, Shiting L, Wenchuan Z. CXCR4-positive subset of glioma is enriched for cancer stem cells. Oncol Res. 2011;19:555.

21. Singh AK, Arya RK, Trivedi AK, Sanyal S, Baral R, Dormond O, Briscoe DM, Datta D. Chemokine receptor trio: CXCR3, CXCR4 and CXCR7 crosstalk via CXCL11 and CXCL12. Cytokine Growth Factor Rev. 2013;24:41-9.
22. Calinescu A-A, Yadav VN, Carballo E, Kadiyala P, Tran D, Zamler DB, Doherty R, Srikanth M, Lowenstein PR, Castro MG. Survival and proliferation of neural progenitor-derived glioblastomas under hypoxic stress is controlled by a CXCL12/CXCR4 autocrine-positive feedback mechanism. Clin Cancer Res. 2017;23:1250-62.

23. Nicolas G, Kroonen J, Di Valentin E, Matthias D, Alexandre D, Philippe M, Bernard R. Adult mouse subventricular zones stimulate glioblastoma stem cells specific invasion through CXCL12/CXCR4 signaling. Neuro Oncol. 2015; 17:81-94

24. Mirandola L, Apicella L, Colombo M, Yu Y, Berta DG, Platonova N, Lazzari E, Lancellotti M, Bulfamante G, Cobos E, Chiriva-Internati M, Chiaramonte R. Anti-Notch treatment prevents multiple myeloma cells localization to the bone marrow via the chemokine system CXCR4/SDF1. Leukemia. 2013;27:1558-66

25. Xiao W, Gao Z, Duan Y, Yuan W, Ke Y. Notch signaling plays a crucial role in cancer stem-like cells maintaining stemness and mediating chemotaxis in renal cell carcinoma. J Exp Clin Cancer Res. 2017:36:41.

26. Rzadzinska AK, Schneider ME, Davies C, Riordan GP, Kachar B. An actin molecular treadmill and Myosins maintain Stereocilia functional architecture and self-renewal. J Cell Biol. 2004;164:887-97.

27. Fife CM, Mccarroll JA, Kavallaris M. Movers and shakers: cell cytoskeleton in cancer metastasis. Br J Pharmacol. 2014;171:5507-23.

28. Qiang L, Yang Y, Ma YJ, Chen FH, Zhang LB, Liu W, Qi Q, Lu N, Tao L, Wang $X T$. Isolation and characterization of cancer stem like cells in human glioblastoma cell lines. Cancer Lett. 2009;279:13-21.

29. Cenciarelli C, Marei HE, Zonfrillo M, Casalbore P, Felsani A, Giannetti S, Trevisi G, Althani A, Mangiola A. The interference of Notch1 target Hes1 affects cell growth, differentiation and invasiveness of glioblastoma stem cells through modulation of multiple oncogenic targets, Oncotarget, 8; 2017.

30. Hu Y-Y, Zheng M-H, Cheng G, Li L, Liang L, Gao F, Wei Y-N, Fu L-A, $\mathrm{Han} \mathrm{H}$. Notch signaling contributes to the maintenance of both normal neural stem cells and patient-derived glioma stem cells. BMC Cancer. 2011;11:82.

31. Mendes RD, Cantébarrett K, Pieters R, Meijerink JP. The relevance of PTENAKT in relation to NOTCH1-directed treatment strategies in T-cell acute lymphoblastic leukemia. Haematologica. 2016;101:1010.

32. Graziani I, Eliasz S, De Marco MA, Chen Y, Pass HI, De May RM, Strack PR, Miele L, Bocchetta M. Opposite effects of Notch-1 and Notch-2 on mesothelioma cell survival under hypoxia are exerted through the Akt pathway. Cancer Res. 2008:68:9678.

33. Chiaramonte R, Colombo M, Bulfamante G, Falleni M, Tosi D, Garavelli S, De SD, Vigolo E, Todoerti K, Neri A. Notch pathway promotes ovarian cancer growth and migration via CXCR4/SDF1a chemokine system. Int J Biochem Cell Biol. 2015:66:134-40.

34. Ping YF, Yao XH, Jiang JY, Zhao LT, Yu SC, Jiang T, Lin MC, Chen JH, Wang B, Zhang R. The chemokine CXCL12 and its receptor CXCR4 promote glioma stem cell-mediated VEGF production and tumour angiogenesis via PI3K/AKT signalling. J Pathol. 2011;224:344.

35. Fan X, Khaki L, Zhu TS, Soules ME, Talsma CE, Gul N, Koh C, Zhang J, Li YM, Maciaczyk J. NOTCH Pathway Blockade Depletes CD133-Positive Glioblastoma Cells and Inhibits Growth of Tumor Neurospheres and Xenografts. Stem Cells. 2010;28:5-16.

36. Zhang Y, Xu W, Guo H, Zhang Y, He Y, Lee SH, Song X, Li X, Guo Y, Zhao Y. NOTCH1 Signaling Regulates Self-Renewal and Platinum Chemoresistance of Cancer Stem-like Cells in Human Non-Small Cell Lung Cancer. Cancer Res. 2017;77:3082-91.

37. Chu Q, Orr BA, Semenkow S, Bar EE, Eberhart CG. Prolonged inhibition of glioblastoma xenograft initiation and clonogenic growth following in vivo Notch blockade. Clin Cancer Res. 2013;19:3224

38. Palomero T, Dominguez M, Ferrando AA. The role of the PTEN/AKT pathway in NOTCH1-induced leukemia. Cell Cycle. 2008;7:965-70.

39. Shepherd C, Banerjee L, Cheung CW, Mansour MR, Jenkinson S, Gale RE, Khwaja A. PI3K|[sol]|mTOR inhibition upregulates NOTCH-MYC signalling leading to an impaired cytotoxic response. Leukemia. 2013; 27:650-60.

40. Baker AT, Zlobin A, Osipo C. Notch-EGFR/HER2 bidirectional crosstalk in breast Cancer. Front Oncol. 2014:4:360.

41. Lin $H$, Xiong W, Zhang X, Liu B, Zhang W, Zhang Y, Cheng J, Huang H. Notch-1 activation-dependent p53 restoration contributes to resveratrolinduced apoptosis in glioblastoma cells. Oncol Rep. 2011;26:925-30. 
42. Schulte A, Günther HS, Phillips HS, Kemming D, Martens T, Kharbanda S, Soriano RH, Modrusan Z, Zapf S, Westphal M. A distinct subset of glioma cell lines with stem cell-like properties reflects the transcriptional phenotype of glioblastomas and overexpresses CXCR4 as therapeutic target. Glia. 2011; 59:590-602.

43. Tabouret E, Tchoghandjian A, Denicolai E, Delfino C, Metellus P, Graillon T, Boucard C, Nanni I, Padovani L, Ouafik LH. Recurrence of glioblastoma after radio-chemotherapy is associated with an angiogenic switch to the CXCL12-CXCR4 pathway. Oncotarget. 2015;6:11664.

44. Yadav VN, Zamler D, Baker GJ, Kadiyala P, Erdreichepstein A, Decarvalho AC, Mikkelsen T, Castro MG, Lowenstein PR. CXCR4 increases in-vivo glioma perivascular invasion, and reduces radiation induced apoptosis: a genetic knockdown study. Oncotarget. 2016;7:83701-19.

45. Liang Z, Brooks J, Willard M, Liang K, Yoon Y, Kang S, Shim H. CXCR4/ CXCL12 axis promotes VEGF-mediated tumor angiogenesis through Akt signaling pathway. Biochem Biophys Res Commun. 2007;359:716-22

46. Xie J, Wang W, Si JW, Miao XY, Li JC, Wang YC, Wang ZR, Ma J, Zhao XC, Li Z. Notch signaling regulates CXCR4 expression and the migration of mesenchymal stem cells. Cell Immunol. 2013;281:68-75.

\section{Publisher's Note}

Springer Nature remains neutral with regard to jurisdictional claims in published maps and institutional affiliations.

Ready to submit your research? Choose BMC and benefit from:

- fast, convenient online submission

- thorough peer review by experienced researchers in your field

- rapid publication on acceptance

- support for research data, including large and complex data types

- gold Open Access which fosters wider collaboration and increased citations

- maximum visibility for your research: over $100 \mathrm{M}$ website views per year

At $\mathrm{BMC}$, research is always in progress.

Learn more biomedcentral.com/submissions 